\title{
Arrhythmogenic Risk and Mechanisms of QT- Prolonging Drugs to Treat COVID-19
}

\author{
Marco Schiavone, MD ${ }^{a, *}$, Alessio Gasperetti, MD ${ }^{a, b}$, Elisa Gherbesi, MD , \\ Luca Bergamaschi, MDa, Roberto Arosio, $\mathrm{MD}^{\mathrm{a}}$, \\ Gianfranco Mitacchione, MD, PhD ${ }^{a}$, Maurizio Viecca, $\mathrm{MD}^{\mathrm{a}}$, \\ Giovanni B. Forleo, MD, PhD ${ }^{a}$
}

\section{KEYWORDS}

- QT interval • COVID-19 • Ventricular arrhythmias • Torsade de point • Hydroxychloroquine

- Antivirals

\section{KEY POINTS}

- COVID-19 patients might experience an increased arrhythmic risk due to QT prolongation, as for their clinical status or for the massive off-label use of potentially QT-prolonging drugs.

- In such patients, a complete baseline QT assessment at a 12-lead ECG should be performed, as well as with Tisdale score calculation and ECG monitoring during drug administration.

- Among the most important clinical factors predisposing to QT prolongation and ventricular arrhythmias, genetic predisposition, older age, female gender, electrolyte disorders, pharmacologic interactions, and bradycardia represent the most relevant features.

- Chloroquine and hydroxychloroquine are associated with QT prolongation especially when used in combination with macrolides, such as azithromycin, or fluoroquinolones.

- A scarce body of evidence exists on antivirals and immunomodulators, with lopinavir/ritonavir appearing to be the most frequently associated with QT prolongation.

\section{INTRODUCTION}

Apart from a well-known respiratory involvement, ${ }^{1,2}$ several reports have described the presence of a significant myocardial injury in coronavirus disease (COVID-19), often sustained by macrothrombosis and microthrombosis, as well as a direct cardiac damage. ${ }^{3-10}$ Indeed, as highlighted in different studies, acute coronary syndromes and cardiac arrhythmias have been reported as potential complications in hospitalized patients, often impairing COVID-19 patients' prognosis. ${ }^{11-18}$ Besides a disease-related cardiac involvement, the massive off-label use of several drugs, ${ }^{19,20}$ including immunosuppressive agents (eg, anakinra or tocilizumab), different antivirals (eg, oseltamivir, remdesivir, or the lopinavir/ritonavir combination), and antimalarial drugs such as chloroquine (CQ) and hydroxychloroquine (HCQ) with or without azithromycin (AM), has generated concerns in the early phase of the pandemic because of their possible arrhythmogenic effects in relation to QT interval prolongation. Indeed, some of these drugs have never been used on a large scale and little is known about their possible arrhythmogenic effects in elderly, critically ill patients, often showing multiple comorbidities, being treated with multiple drugs. Most of these drugs

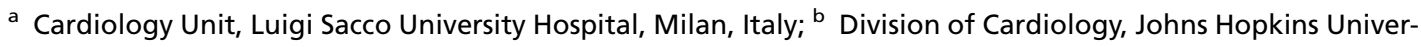
sity, Baltimore, MD, USA

* Corresponding author: Luigi Sacco University Hospital, Via G.B. Grassi 74, Milan 20157, Italy.

E-mail address: marco.schiavone11@gmail.com
} 
may prolong the QT interval both with direct (channel blocking activity) or indirect effects (eg, liver and/or kidney toxicity, cytochrome interactions, electrolyte imbalance), potentially increasing the arrhythmic (eg, Torsade de Pointes [TdP]) and nonarrhythmic mortality. The aim of this work is to summarize the underlying arrhythmogenic mechanisms related to the use of potentially QTprolonging drugs used during the COVID-19 pandemic.

\section{THE QT INTERVAL}

The QT interval is the interval from the beginning of ventricular depolarization to the completion of the repolarization of the entire ventricular mass. Ideally, the QT interval should be measured at a paper rate of $25 \mathrm{~mm} / \mathrm{s}$ from the beginning of the QRS until the return to baseline of the $T$ wave. The QT interval should be calculated in a total of 6 leads, with 3 leads taken from peripheral leads (avoiding DIII and aVR because of frequent low voltages and inverted polarity, respectively) and 3 precordial leads (preferably V2, V4, and V6). The QT value should be derived from the median of the 6 individual leads. Although QT calculation is a well-known and standardized methodology, a correct and consistent measurement of the QT interval is always difficult to obtain in clinical practice. Deciding if QT interval is normal or prolonged is often challenging, as reported by Viskin and colleagues, underlining that most physicians, including many cardiologists, cannot accurately calculate a QT and cannot correctly identify a long QT. ${ }^{21}$ Moreover, as the heart rate is the major determinant of the QT interval, a corrected QT interval value (QTC) should always be preferred in clinical practice. Several formulae may commonly be adopted to calculate QTc, with the Bazett formula being the most frequently used. Nevertheless, Vandenberk and colleagues ${ }^{22}$ showed that the Bazett formula may overestimate the number of patients at potential risk of dangerous QTc prolongation when compared with Fridericia and Framingham formulae. To sum up different clinical data, the Framingham formula still seems to be the best choice to predict drug-induced QTc prolongation. ${ }^{23}$ Different cut-offs have been traditionally proposed to define when a QTc is prolonged, with the most significantly reliable being 450 msec, with values of greater than $500 \mathrm{msec}$ being considered definitely abnormal and potentially arrhythmogenic $^{24,25}$; thus, drug-induced changes in QTc of greater than 50 msec are often used as safety endpoints when evaluating drug effects and may justify a treatment interruption. A proposed algorithm to identify patients at risk of developing ventricular arrhythmias (VAs) when treating with one or more QT-prolonging drugs during the COVID-19 pandemic is reported in Fig. 1.

\section{MECHANISMS OF QT PROLONGATION}

QT prolongation is associated with an increase in both arrhythmic and nonarrhythmic mortality, and it is often used as a metric of drug safety. ${ }^{26}$ Indeed, QT prolongation is related to a mix of modifiable and unmodifiable risk factors that may determine why at same drugs dosages, drug-induced longQT may happen only in some cases. Druginduced effects are one of the most frequent reasons for QT prolongation: an updated list of the medications associated with QT prolongation and risk of $\mathrm{TdP}$ is reported on https://www. crediblemeds.org. It should be noted that, besides the direct impact of some medications on the QT interval, drug-to-drug and drug-to-cytochrome interactions should always be considered, especially in COVID-19, when assessing the risk of QT prolongation in the COVID-19 clinical setting.

\section{Nonmodifiable Risk Factors}

Genetic background, as well as older age and female gender, are the most important unmodifiable risk factors. Long QT syndrome (LQTS) represents a heterogeneous family of inherited primary arrhythmia syndromes characterized by QT interval prolongation and T-wave abnormalities on the ECG. Patients affected by LQTS have been identified all over the world and in all ethnic groups; among Caucasians, the prevalence of LQTS has been 1:2000 apparently healthy newborns. ${ }^{27}$ Risks of VAs related to LQTS are mainly due to adrenergic activation, and the annual rate of sudden cardiac death (SCD) in patients with untreated LQTS is estimated to be between $0.33 \%$ and $0.9 \%{ }^{28,29}$ Mutations in 13 genes have been traditionally associated with LQTS - among those, mutations in potassium-channel genes KCNQ1 (LQT1 locus) and KCNH2 (LQT2 locus) and the sodiumchannel gene SCN5A (LQT3 locus) are the most common causes of the LQTS and account for approximately $75 \%$ of cases. ${ }^{30}$ Once diagnosis is made, risk stratification is mandatory to tailor lifestyle changes and to deliver the adequate therapy, such as implantable cardioverter-defibrillator (ICD) in high-risk patients, with the modern subcutaneous ICD potentially being the most appropriate therapeutic option. ${ }^{31-35}$ All LQTS patients, regardless of the SCD risk, should avoid QTprolonging drugs, promptly correct electrolyte abnormalities (hypokalemia, hypomagnesemia, and hypocalcemia) that may occur during diarrhea, 


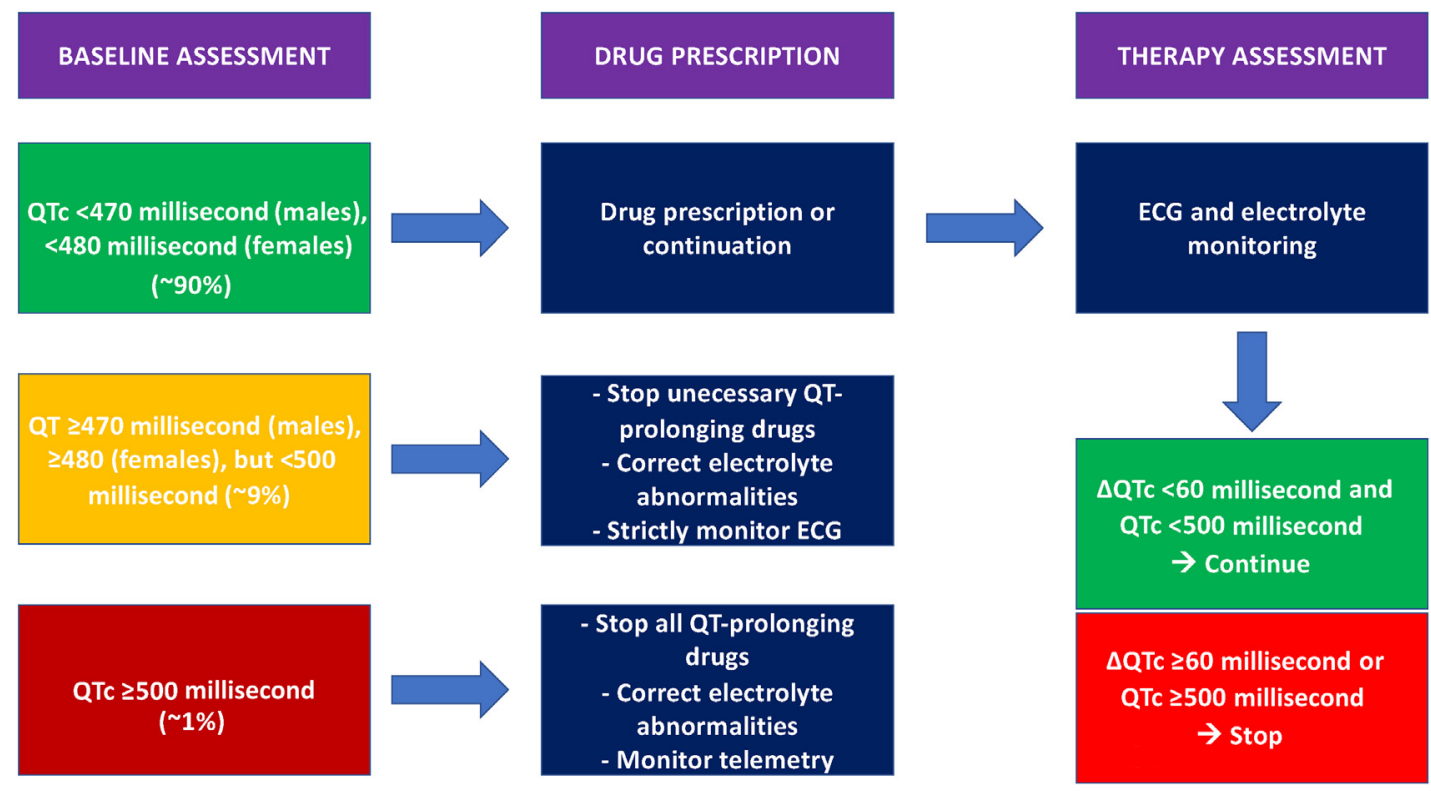

Fig. 1. Proposed algorithm to identify patients at risk of developing ventricular arrhythmias when treating with one or more QT-prolonging drugs. (Adapted from Giudicessi JR, Noseworthy PA, Friedman PA, Ackerman MJ. Urgent Guidance for Navigating and Circumventing the QTc-Prolonging and Torsadogenic Potential of Possible Pharmacotherapies for Coronavirus Disease 19 (COVID-19). Mayo Clin Proc. 2020;95(6):1213-1221. https://doi. org/10.1016/j.mayocp.2020.03.024; with permission)

vomiting, or metabolic conditions and avoid genotype-specific triggers for arrhythmias (strenuous swimming, especially in LQTS1, and exposure to loud noises in LQTS2 patients). ${ }^{36}$ There are more than 260 medicines on the "drugs to avoid" list for patients with LQTS, that are generally grouped as follows:

- Known risk: drugs that should never or very rarely use because of clear danger-if administered, LQTS patients should be treated by cardiologists with expertise in arrhythmias management.

- Possible risk: drugs that have been found to increase QT interval and may be dangerous in some LQTS patients - if necessary, those drugs may be prescribed by specialists.

- Conditional risk: drugs that may increase risk in LQTS patients only in certain conditions (eg, overdose, prolonged treatments, use in combination with other drugs that may change their clearance)-most of those drugs can be prescribed safely.

- Special risk: drugs that have a theoretic risk of causing arrhythmias in LQTS patients because of their adrenergic effect-most of those drugs can be prescribed to carefully selected LQTS patients ${ }^{37}$.

Given the pandemic nature of COVID-19, even a rare congenital genetic predisposition, may result in tremendous consequences if undetected, in terms of drug-induced TdP and SCD. The most widely used QT-prolonging drugs that should be avoided in patients with LQTS and their associated risk have been summarized in Table 1.

\section{Modifiable Risk Factors}

Electrolyte abnormalities are the most common modifiable risk factors associated with QT prolongation. Among those, hypokalemia has a particular arrhythmogenic effect, not only prolonging the QT interval but also being a major risk factor for druginduced LQTS as it increases the tendency of $\mathrm{K}_{\mathrm{v}} 11.1$ channels to remain inactivated and decreases repolarizing currents. Hypocalcemia and hypomagnesemia as well may show a QTprolonging effect. Kidney and liver failure have both been associated with the risk of QT prolongation because of their role in metabolite/toxin clearance; finally, bradycardia is a relevant additional risk factor.

Patients accessing intensive care such as COVID-19 severe infections should therefore be strictly monitored because of their potential exposure to these risk factors. Lastly, to estimate the risk of drug-induced QT prolongation, all the patients treated with a potential QT-prolonging drug should be evaluated with a Tisdale score at baseline (Table 2) ${ }^{38}$ Indeed, the Tisdale risk classes are, respectively, associated with 15\%, 37\%, 


\begin{tabular}{|c|c|c|c|c|c|}
\hline Risk & AAD & AB/AFA/AM & AP/AD & Anesthetic & Other \\
\hline Known & $\begin{array}{l}\text { Amiodarone } \\
\text { Dronedarone } \\
\text { Disopyramide } \\
\text { Dofetilide } \\
\text { Flecainide } \\
\text { lbutilide } \\
\text { Procainamide } \\
\text { Quinidine } \\
\text { Sotalol }\end{array}$ & $\begin{array}{l}\text { Azithromycin } \\
\text { Ciprofloxacin } \\
\text { Clarithromycin } \\
\text { Erythromycin } \\
\text { Fluconazole } \\
\text { Gatifloxacin } \\
\text { Levofloxacin } \\
\text { Moxifloxacin } \\
\text { Roxithromycin } \\
\text { Chloroquine } \\
\text { Hydroxychloroquine }\end{array}$ & $\begin{array}{l}\text { Chlorpromazine } \\
\text { Citalopram }\end{array}$ & $\begin{array}{l}\text { Propofol } \\
\text { Sevoflurane }\end{array}$ & $\begin{array}{l}\text { Cocaine } \\
\text { Methadone } \\
\text { Domperidone } \\
\text { Levosulpiride } \\
\text { Ondansetron } \\
\text { Other antineoplastic } \\
\quad \text { drugs }\end{array}$ \\
\hline Possible & & $\begin{array}{l}\text { Norfloxacin } \\
\text { Ofloxacin }\end{array}$ & $\begin{array}{l}\text { Lithium } \\
\text { Venlafaxine } \\
\text { Aripiprazole } \\
\text { Clozapine }\end{array}$ & Tramadol & $\begin{array}{l}\text { Alfuzosin } \\
\text { Nicardipine } \\
\text { Oxytocin } \\
\text { Other antineoplastic } \\
\text { drugs } \\
\end{array}$ \\
\hline Conditional & $\begin{array}{l}\text { Ivabradine } \\
\text { Propafenone } \\
\text { Ranolazine }\end{array}$ & $\begin{array}{l}\text { Piperacillin/ } \\
\text { tazobactam } \\
\text { Amphotericin B } \\
\text { Ketoconazole } \\
\text { Metronidazole } \\
\text { Voriconazole }\end{array}$ & $\begin{array}{l}\text { Amisulpride } \\
\text { Amitriptyline } \\
\text { Fluoxetine } \\
\text { Olanzapine } \\
\text { Paroxetine } \\
\text { Quetiapine } \\
\text { Risperidone } \\
\text { Sertraline } \\
\text { Trazodone }\end{array}$ & & $\begin{array}{l}\text { Hydrochlorothiazide } \\
\text { Torasemide } \\
\text { Amantadine } \\
\text { Indapamide } \\
\text { Furosemide } \\
\text { Loperamide } \\
\text { Metolazone } \\
\text { Metoclopramide } \\
\text { Omeprazole } \\
\text { Lansoprazole } \\
\text { Pantoprazole } \\
\text { Esomeprazole }\end{array}$ \\
\hline
\end{tabular}

Abbreviations: $A A D$, antiarrhythmic drugs; $A B$, antibiotics; $A D$, antidepressants; $A D H D$, attention-deficit hyperactivity disorder; AFA, antifungal agents; AM, antimalarials; AP, antipsychotics.

and $73 \%$ risk of QT prolongation, and can be extremely useful for a quick but reliable baseline risk assessment.

\section{QT-PROLONGING DRUGS AND ARRHYTHMOGENIC RISK IN COVID-19}

While waiting for the massive vaccination campaign to be completed to reach the herd immunity, several drugs proposed as potential treatments are still used worldwide to treat COVID-19. However, most of these drugs are not specific and targeted against SARS-CoV-2, so that using preexisting drugs has represented a fast and very useful strategy with known safety, characteristics, and dosage used during the early and even late phase of the pandemic. ${ }^{19}$ If some of these drugs have been investigated for their efficacy and safety in treating COVID-19, some others are still undergoing clinical trials to test their profile. One of the main concerns regarding the use of some of these repurposed drugs is the potential impact on the QT interval and their arrhythmogenic effects, which is particularly noteworthy because of the common coprescription of several drugs that may show combined effects on the QT interval, as well as several clinical characteristics that may eventually lead to arrhythmic manifestations. ${ }^{39}$ The knowledge on these potential adverse events is mostly derived from the historical data collected according to the European Union Drug Regulatory Authorities (EUDRA) vigilance by the European Medical Agency (EMA). If data on chloroquine (CQ) and hydroxychloroquine (HCQ) are more robust, data on other less commonly used drugs are weaker.

\section{Antimalarial Agents}

$\mathrm{CQ}$ and $\mathrm{HCQ}$ are antimalarial drugs that inhibit lysosomes functions increasing $\mathrm{pH}$ and thereby blocking endosome-mediated entry. These drugs can also interfere with cell replication, viral protein 


\begin{tabular}{l} 
Table 2 \\
Tisdale score to identify hospitalized patients \\
at risk for QT interval prolongation could lead \\
to interventions to reduce the risk of TdP ${ }^{38}$ \\
Age $\geq 68$ y \\
$\begin{array}{l}\text { Female Sex } \\
\text { Loop Diuretic Treatment }\end{array}$ \\
\hline $\begin{array}{l}\text { Serum } \mathrm{K}^{+} \leq 3.5 \mathrm{mEq} / \mathrm{L} \\
\text { Acute myocardial infarction } \\
\text { Admission QTc } \geq 450 \text { msec }\end{array}$ \\
\hline $\begin{array}{l}\text { 1-QTC-prolonging drugs } \\
\text { 2+ QTc-prolong drugs } \\
\text { Sepsis } \\
\text { Heart failure hospitalization }\end{array}$ \\
\hline
\end{tabular}

TISDALE SCORE:

Low risk ( $\leq 6$ points).

Intermediate risk (7-10 points).

High risk ( $\geq 11$ points).

glycosylation, virus assembly, and release. CQ use is restricted because of potential overdose, acute poisoning, and death, whereas HCQ (a derivative of $C Q$ ) has been demonstrated to be far less toxic than CQ. ${ }^{19}$ In the early phase of the pandemic, these antimalarial drugs have been suggested to be effective in treating COVID-19, ${ }^{40}$ and they have been thereby extensively used both in mild and in severe COVID-19. Randomized trials and metanalysis have, however, shown that $\mathrm{HCQ}$ was not effective as it was initially supposed. In the randomized, controlled, open-label RECOVERY trial, ${ }^{41}$ comparing a range of possible treatments with usual care in patients hospitalized with COVID-19, patients receiving HCQ did not have a lower incidence of death at 28 days than those who received usual care. Also, the TOGETHER trial $^{42}$ showed that an early treatment with HCQ did not have any significant benefit in decreasing COVID-19-associated hospitalization or other secondary clinical outcomes. These results were confirmed by Ghazy and colleagues ${ }^{43}$ in a metanalysis, showing that neither $\mathrm{CQ}$ nor HCQ were able to decrease mortality, improve virological cure, reduce the risk for noninvasive ventilation and shorten the conversion to negative polymerase chain reaction, prevent radiological progression, and affect clinical worsening of the disease. Considering this evidence, showing a complete lack of efficacy and an increase in adverse events, most American and European medical associations and drugs associations do not recommend the use of $\mathrm{HCQ}$ in hospitalized COVID-19 patients and in the early stages of the disease.

Nevertheless, several trials have been performed to test the cardiac safety of $\mathrm{CQ} / \mathrm{HCQ}$ in the early phase of the pandemic, and although their results may now appear outdated in the light of this recent discovery of CQ/HCQ inefficacy in COVID-19, all these analyses gave the scientific community the possibility to test these drugs during a mass-use on critically ill patients. The importance of these reports is undoubtedly related to the idea that $C Q$ and $H C Q$ are known to be associated with a risk of QT prolongation, so that they are classified as drugs associated with $\mathrm{TdP}$ on the Credible Meds Web site. Hence, between $0.5 \%$ and $2 \%$ of all the side effects of these drugs reported to the European Medicines Agency (EMA) are major arrhythmic events with non-negligible rates of cardiac arrest. Moreover, is noteworthy to underline that $\mathrm{HCQ}$, besides malaria, is currently used to treat discoid or systemic lupus erythematosus, rheumatoid arthritis (RA), and systemic sclerosis.

Indeed, research on this topic is beneficial to better understand its arrhythmic safety also for these patients. Specifically, Gasperetti and colleagues extensively evaluated the arrhythmic safety of $\mathrm{HCQ}$ in different clinical settings. ${ }^{44}$ In this study, enrolled patients were followed in 3 different clinical settings, defined as home management, medical ward, or intensive care unit (ICU) management, depending on the COVID-19 severity, and were all tested through serial ECG monitoring. The authors concluded that $\mathrm{HCQ}$ administration, alone or in combination with other potentially QTc-prolonging drugs, although potentially causing only modest QTC prolongation, did not result in significant arrhythmic events, representing a safe option for patients with COVID-19 infection. Indeed, no TdP were noticed in the entire cohort, and the described ventricular fibrillation (VF) events occurred in the ICU cohort, with acute myocardial infarction as the underlying cause. These results were confirmed by 3 different studies, enrolling patients with COVID-19 treated with HCQ. First, Mazzanti and colleagues ${ }^{45}$ did not document any life-threatening arrhythmic event, with only a modest effect on QTc prolongation, that was attributed to the short duration of HCQ treatment in COVID-19, as HCQ reaches the steady state after 180 days of HCQ therapy. ${ }^{46}$ Therefore, caution should be adopted when extending these safety results to patients treated for several years for other indications, that could experience a more severe QTC prolongation and related arrhythmic effects. The authors recommend to always perform a baseline ECG before starting $\mathrm{HCQ}$, followed by a subsequent recording "on therapy" for patients with a normal baseline QTc, with an advisable daily monitoring for patients with baseline QTc greater than $480 \mathrm{msec}$. 
Furthermore, Bernardini and colleagues ${ }^{47}$ and Chorin and colleagues ${ }^{48}$ evaluated the safety of the HCQ plus AM combination regimen that might surely have higher proarrhythmic effects than $\mathrm{HCQ}$ alone. In both cohorts, a significant increase of QT interval was noted, especially in the elderly, with $8 \%$ and $23 \%$ patients treated with $\mathrm{HCQ}+\mathrm{AM}$ showing a QTC greater than $500 \mathrm{msec}$, respectively. Besides this difference, if in the first cohort no arrhythmic fatalities occurred, in the second one QT prolongation has led to 1 life-threatening arrhythmia $(0.4 \%)$ in the form of TdP. These dissimilarities might be due to concurrent modifiable risk factors, such as electrolyte imbalance, comorbidities, or COVID-19 severity, that could have contributed to QT prolongation. Indeed, the safety of HCQ large-scale use in acutely ill patients with multiple comorbidities, possibly receiving several QT-prolonging drugs and potentially at risk of electrolyte disbalance, still needs to be properly tested. Even if data point toward a general arrhythmic safety of $H C Q$, especially when used alone or in the short-term period, a baseline ECG and a periodic QTc interval monitoring should be advisable when this drug regimen is given.

\section{Antiviral Drugs}

\section{Lopinavir/ritonavir}

Lopinavir and ritonavir (LPV/RTN) are antiretroviral protease inhibitors that are used in combination to treat human immunodeficiency virus. RTN increases the half-life of LPV by inhibiting the halflife of cytochrome P450 half-life, and thereby acting as a pharmacokinetic enhancer; LPV acts against viral 3-chymotrypsin-like protease (3CLpro). This combination has shown promising in vitro results against SARS-CoV and MERS$\mathrm{CoV}$, but clinical randomized trials did show no benefit with LPV/RTN combination beyond standard of care in hospitalized adult patients with severe COVID-19. ${ }^{49}$ Nevertheless, some researchers, interpreting the findings of this clinical trial, suggested the earlier usage of LPV/RTN in the course of the disease may be overall beneficial in some cases. ${ }^{50}$ Therefore, the evaluation of the arrhythmogenic effects is of pivotal importance. Indeed, this combination has an intrinsic risk of ventricular tachycardia $(0.03 \%)$, VF (0.03\%), and TdP $(0.09 \%)$ reported in the literature, according to the EUDRA vigilance from EMA. During the pandemic, Haghjoo and colleagues $^{51}$ investigated the potential QTprolonging role of LPV/RTN, showing a significant increase in QTc during drug therapy (along with $\mathrm{CQ}, \mathrm{HCQ}$, atazanavir/ritonavir, oseltamivir, favipiravir, and remdesivir alone in combination with
AM). Nevertheless, in this cohort, TdP occurred overall rarely $(n=9 ; 0.385)$, with 4 patients treated with $\mathrm{HCQ}+\mathrm{AM}$, whereas 5 patients were treated with LPN/RTV + AM. Interestingly, in this analysis, although critical QT prolongation was associated with a higher risk of $\mathrm{TdP}$, only treatment with LPN/RTV, simultaneous administration of amiodarone (known to prolong QT interval ${ }^{52}$ ) or furosemide and hypokalemia could predict the occurrence of TdP in this cohort; instead, HCQ use was only modestly associated with TdP ( $0.3 \%$ of patients). Other cases of QT prolongation with LPN/RTV treatment have been described during the pandemic, ${ }^{53}$ so that careful QTc duration evaluation and monitoring should be performed at baseline and during this drug therapy to identify patients at high risk of arrhythmias.

\section{Remdesivir}

Remdesivir is an adenosine analog that inserts itself into viral RNA chains, blocking viral replication. Although nothing has been reported in the FDA and EMA databases regarding links with QT prolongation, some case reports and scarce data have suggested that also this drug may prolong QT, as well as induce sinus bradycardia, as reported by Gupta and colleagues. ${ }^{54}$ It should be noted that in this case, patients were also on AM while receiving remdesivir, which is well-known to prolong the QT interval. Remdesivir monotherapy has indeed shown to prolong QTc in the Haghjoo and colleagues ${ }^{51}$ analysis, although keeping a low-risk profile in terms of QT prolongation and TdP induction. Moreover, no major cardiac arrhythmia events were described in the largest trial assessing remdesivir efficacy and safety profile. Nevertheless, cardiac safety of remdesivir remains largely uncertain and these effects were described as reversible upon stopping remdesivir therapy, caution should be taken with this antiviral agent.

\section{Favipiravir}

Favipiravir is a guanine analog that selectively inhibits viral RNA-dependent RNA polymerase and it was approved for influenza and Ebola virus infection. Çap and colleagues ${ }^{55}$ specifically evaluated any change in the QTc interval in patients who were hospitalized due to COVID-19, receiving favipiravir treatment. No significant QTc prolongation was noted with monotherapy, when compared to $\mathrm{HCQ}$ or $\mathrm{HCQ}+$ favipiravir. On the other side, Haghjoo and colleagues ${ }^{51}$ observed a mild QTC prolongation in most cases, without TdP events, even if they concluded that favipiravir monotherapy was safer than other COVID-19 mediations in terms of QTc prolongation. 


\section{Oseltamivir}

Oseltamivir is an antiviral drug that inhibits neuraminidase, expressed on the viral surface, which plays an essential role in viral entry to host cells, viral release from infected cells, and subsequent viral spread. Although its role in COVID-19 is very limited, it is noteworthy to mention that Haghjoo and colleagues $^{51}$ reported that this drug may significantly prolong QTc when used in combination with HCQ, as also suggested by Çelik and colleagues. ${ }^{56}$ No TdP were noted in these patients, as in previous preclinical models that tested oseltamivir therapy alone, as this drug is capable to inhibit both inward and outward currents. ${ }^{57}$ However, caution should be taken when prescribing oseltamivir plus other COVID-19 medications potentially prolonging QTc during the influenza season.

\section{Antibacterial Drugs}

\section{Azithromycin}

AM, a macrolide antibacterial agent, has an established role against a broad spectrum of grampositive and gram-negative agents, as well as act as an immunomodulator. During the COVID19 pandemic, it has been used in combination with $\mathrm{HCQ}$ because of promising in vitro findings, even further clinical trials have demonstrated that a routine use of $A M$ for reducing time to recovery or risk of hospitalization for people with suspected COVID-19 in the community was not justified. ${ }^{58}$ AM is a well-known QT-prolonging drug, that should be avoided in all LQTS cases, even when used as a stand-alone therapy. The arrhythmogenic potential of AM has been discussed in the previous sections when assessing the combination of this drug with HCQ. Indeed, in the PRINClPLE trial, ${ }^{58}$ no difference was found regarding a prolonged QTc interval between the AM group and the standard care group, but a QTc interval prolongation was most common in the $\mathrm{HCQ}+\mathrm{AM}$ group.

\section{Immunomodulators}

\section{Tocilizumab}

Tocilizumab (TCZ) is an anti-interleukin (IL)-6 receptor antibody that potently inhibits inflammatory activation and is used to treat RA, systemic juvenile idiopathic arthritis, and chimeric antigen receptor-cell-induced cytokine release syndrome. In a clinical trial conducted on patients with RA, Lazzerini and colleagues ${ }^{59}$ showed that TCZ treatment was associated with a rapid and significant reduction to mean values less than $440 \mathrm{msec}$ in patients who had prolonged QTc interval at baseline. This effect seems to be driven by TCZ action against systemic inflammation, thus providing further evidence of the close correlation between the degree of systemic inflammation and QTC duration in RA patients. ${ }^{60}$ In this light, the administration of anti-IL-6 targeted therapies (TCZ, sarilumab) to patients with COVID-19, particularly those severely ill, has been supposed not only to promote the recovery from multiorgan dysfunction but also mitigate the associated high arrhythmic risk, in the early phase of the pandemic. However, randomized trials have shown that the use of TCZ did not result in significantly better clinical status or lower mortality than placebo at 28 days, being not effective for preventing intubation or death in moderately ill hospitalized patients with COVID$19 .{ }^{61,62}$ Specific data on the supposed antiarrhythmic effects, associated with the antiinflammatory effects, were not specifically reported.

\section{Sarilumab}

Sarilumab (SAR) is a humanized monoclonal antibody, inhibiting the IL-6 receptor; it is approved for the treatment of adults with moderately to severely active RA. The rate of cardiovascular arrest reported in the EMA registry is relatively high (3.2\%). Nevertheless, no specific data concerning QT prolongation and/or VAs in patients treated with SAR have been reported, and even a protective role (similar to TCZ) has been otherwise suggested, because of its immunomodulating effect, potentially decreasing the extent of myocardial injury frequently observed in COVID-19. ${ }^{63} \mathrm{Howev}$ er, data in COVID-19 are scarce, and specific investigations on its effect on QT interval are lacking.

\section{IL-1 inhibitors (anakinra and canakinumab)}

Anakinra (ANA) and canakinumab (CAN) are the only 2 IL-1 inhibitors approved in Europe. Owing to the massive COVID-19 inflammatory reaction, it has been suggested that intravenous ANA and CAN could be used against the cytokine storm that seems to be associated with some extent of the lung damage in COVID-19. A metanalysis has shown that the administration of ANA in COVID19 patients could be associated with reductions in both mortality and need for mechanical ventilation. ${ }^{64}$ As for TCZ and SAR, specific data on the proarrhythmic or antiarrhythmic effect are lacking.

\section{SUMMARY}

Severe systemic inflammation and the off-label use of some drugs in COVID-19 may significantly prolong the QTc interval, potentially leading to a non-negligible risk of VAs. Among these drugs, $\mathrm{CQ}$ and $\mathrm{HCQ}$ have shown the higher risk of QTC prolongation and $\mathrm{TdP}$, that is, however, overall 
low, even in association with other QT-prolonging drugs, such as AM.

In line with other authors, ${ }^{65}$ also this panel believes that the ultimate aim of QTc surveillance during the COVID-19 pandemic should not result in an exclusion from potentially beneficial treatments or experimental clinic trials, but instead to identify patients at risk, in order to counterbalance and mitigate all potentially drug-induced arrhythmogenic side-effects.

\section{CLINICS CARE POINTS}

- Arrhythmic risk assessment is of pivotal importance when administering drug therapy in COVID-19.

- Several drugs may prolong QT interval in COVID-19, and particular attention should be paid to specific drugs combinations (e.g. chloroquine and hydroxychloroquine + macrolides).

\section{REFERENCES}

1. Gattinoni L, Coppola S, Cressoni M, et al. COVID-19 does not lead to a "typical" acute respiratory distress syndrome. Am J Respir Crit Care Med 2020;201(10):1299-300.

2. Busana M, Gasperetti A, Giosa L, et al. Prevalence and outcome of silent hypoxemia in COVID-19. Minerva Anestesiol 2021;87(3):325-33.

3. Zhou F, Yu T, Du R, et al. Clinical course and risk factors for mortality of adult inpatients with COVID-19 in Wuhan, China: a retrospective cohort study. Lancet 2020;395(10229): 1054-62.

4. Wang D, Hu B, Hu C, et al. Clinical characteristics of 138 hospitalized patients with 2019 novel coronavirus-infected pneumonia in Wuhan, China. JAMA 2020;323(11):1061-9.

5. Huang C, Wang Y, Li X, et al. Clinical features of patients infected with 2019 novel coronavirus in Wuhan, China. Lancet 2020;395(10223):497-506.

6. Schiavone M, Gasperetti A, Mancone M, et al. Oral anticoagulation and clinical outcomes in COVID19: an Italian multicenter experience. Int J Cardiol 2021;323:276-80.

7. Levi M, Thachil J, Iba T, et al. Coagulation abnormalities and thrombosis in patients with COVID-19. Lancet Haematol 2020;7(6):e438-40.

8. Ackermann M, Verleden SE, Kuehnel M, et al. Pulmonary vascular endothelialitis, thrombosis, and angiogenesis in Covid-19. N Engl J Med 2020; 383(2):120-8.
9. Schiavone M, Gasperetti A, Mancone M, et al. Redefining the prognostic value of high-sensitivity troponin in COVID-19 patients: the importance of concomitant coronary artery disease. J Clin Med 2020;9(10):3263.

10. Della Rocca DG, Magnocavallo M, Lavalle C, et al. Evidence of systemic endothelial injury and microthrombosis in hospitalized COVID-19 patients at different stages of the disease. J Thromb Thrombolysis 2021;51(3):571-6.

11. Shi S, Qin M, Shen B, et al. Association of cardiac injury with mortality in hospitalized patients with COVID-19 in Wuhan, China. JAMA Cardiol 2020; $5(7): 802-10$.

12. Wei JF, Huang FY, Xiong TY, et al. Acute myocardial injury is common in patients with COVID-19 and impairs their prognosis. Heart 2020;106(15):1154-9.

13. Lala A, Johnson KW, Januzzi JL, et al. Prevalence and impact of myocardial injury in patients hospitalized with COVID-19 infection. J Am Coll Cardiol 2020;76(5):533-46.

14. Schiavone M, Gobbi C, Biondi-Zoccai G, et al. Acute coronary syndromes and Covid-19: exploring the uncertainties. J Clin Med 2020;9(6):1683.

15. Li X, Guan B, Su T, et al. Impact of cardiovascular disease and cardiac injury on in-hospital mortality in patients with COVID-19: a systematic review and meta-analysis. Heart 2020;106(15):1142-7.

16. Mitacchione G, Schiavone M, Gasperetti A, et al. Ventricular tachycardia storm management in a COVID-19 patient: a case report. Eur Hear J Case Rep 2020;4(Fl1):1-6.

17. Antwi-Amoabeng D, Beutler BD, Singh S, et al. Association between electrocardiographic features and mortality in COVID-19 patients. Ann Noninvasive Electrocardiol 2021. https://doi.org/10.1111/ anec. 12833.

18. Romero J, Alviz I, Parides M, et al. T-wave inversion as a manifestation of COVID-19 infection: a case series. J Interv Card Electrophysiol 2020;59(3):485-93.

19. Tarighi P, Eftekhari S, Chizari M, et al. A review of potential suggested drugs for coronavirus disease (COVID-19) treatment. Eur J Pharmacol 2021;895: 173890.

20. Mitacchione G, Schiavone M, Curnis A, et al. Impact of prior statin use on clinical outcomes in COVID-19 patients: data from tertiary referral hospitals during COVID-19 pandemic in Italy. J Clin Lipidol 2021; 15(1):68-78.

21. Viskin S, Rosovski U, Sands AJ, et al. Inaccurate electrocardiographic interpretation of long QT: the majority of physicians cannot recognize a long QT when they see one. Heart Rhythm 2005;2(6):569-74.

22. Vandenberk B, Vandael E, Robyns T, et al. Which QT correction formulae to use for QT monitoring? J Am Heart Assoc 2016;5(6). https://doi.org/10.1161/ JAHA. 116.003264. 
23. Batchvarov VN, Ghuran A, Smetana P, et al. QT-RR relationship in healthy subjects exhibits substantial intersubject variability and high intrasubject stability. Am J Physiol Heart Circ Physiol 2002;282(6). https:// doi.org/10.1152/ajpheart.00860.2001.

24. Postema PG, De Jong JSSG, Van der Bilt IAC, et al. Accurate electrocardiographic assessment of the QT interval: teach the tangent. Heart Rhythm 2008; 5(7):1015-8.

25. Postema PG, Arthur AMW. The measurement of the QT interval. Curr Cardiol Rev 2014;10(3):287-94.

26. Simpson TF, Salazar JW, Vittinghoff E, et al. Association of QT-prolonging medications with risk of autopsy-defined causes of sudden death. JAMA Intern Med 2020;180(5):698-706.

27. Schwartz PJ, Stramba-Badiale M, Crotti L, et al. Prevalence of the congenital long-qt syndrome. Circulation 2009; 120(18):1761-7.

28. Moss AJ, Schwartz PJ, Crampton RS, et al. The long QT syndrome. Prospective longitudinal study of 328 families. Circulation 1991;84(3):1136-44.

29. Priori SG, Schwartz PJ, Napolitano C, et al. Risk stratification in the long-QT syndrome. N Engl J Med 2003;348(19):1866-74.

30. Nakano Y, Shimizu W. Genetics of long-QT syndrome. J Hum Genet 2016;61(1):51-5.

31. Schwartz PJ, Spazzolini C, Priori SG, et al. Who are the long-QT syndrome patients who receive an implantable cardioverter-defibrillator and what happens to them?: data from the European Long-QT syndrome implantable cardioverter-defibrillator (LQTS ICD) registry. Circulation 2010;122(13): 1272-82.

32. Forleo GB, Gasperetti A, Breitenstein A, et al. Subcutaneous implantable cardioverter defibrillator and defibrillation testing: a propensity-matched pilot study. Heart Rhythm 2021. https://doi.org/10.1016/j. hrthm.2021.06.1201.

33. Gasperetti A, Schiavone M, Ziacchi M, et al. Long term complications in patients implanted with subcutaneous implantable defibrillators Real-world data from the Extended ELISIR experience. Heart Rhythm 2021. https://doi.org/10.1016/j.hrthm.2021.07.008.

34. Lambiase PD, Eckardt L, Theuns DA, et al. Evaluation of subcutaneous implantable cardioverterdefibrillator performance in patients with ion channelopathies from the EFFORTLESS cohort and comparison with a meta-analysis of transvenous ICD outcomes. Heart Rhythm O2 2020;1(5):326-35.

35. Gasperetti A, Schiavone M, Ziacchi M, et al. Longterm complications in patients implanted with subcutaneous implantable cardioverter-defibrillators: real-world data from the extended ELISIR experience. Heart Rhythm 2021. https://doi.org/10.1016/j. hrthm.2021.07.008.

36. Schwartz PJ, Priori SG, Spazzolini C, et al. Genotype-phenotype correlation in the long-QT syndrome: gene-specific triggers for lifethreatening arrhythmias. Circulation 2001;103(1): 89-95.

37. Moss AJ, Zareba W, Hall WJ, et al. Effectiveness and limitations of $\beta$-blocker therapy in congenital longQT syndrome. Circulation 2000;101(6):616-23.

38. Tisdale JE, Jaynes HA, Kingery JR, et al. Development and validation of a risk score to predict QT interval prolongation in hospitalized patients. Circ Cardiovasc Qual Outcomes 2013;6(4):479-87.

39. Gasperetti A, Schiavone M, Tondo C, et al. QT interval monitoring and drugs management during COVID-19 pandemic. Curr Clin Pharmacol 2020;15. https://doi. org/10.2174/1574884715666201224155042.

40. Gao J, Tian Z, Yang X. Breakthrough: chloroquine phosphate has shown apparent efficacy in treatment of COVID-19 associated pneumonia in clinical studies. Biosci Trends 2020;14(1):72-3.

41. The RECOVERY Collaborative Group. Effect of hydroxychloroquine in hospitalized patients with Covid-19. N Engl J Med 2020;383(21):2030-40.

42. Reis G, Moreira Silva EADS, Medeiros Silva DC, et al. Effect of early treatment with hydroxychloroquine or lopinavir and ritonavir on risk of hospitalization among patients with COVID-19: the TOGETHER randomized clinical trial. JAMA Netw Open 2021; 4(4):e216468.

43. Ghazy RM, Almaghraby A, Shaaban R, et al. A systematic review and meta-analysis on chloroquine and hydroxychloroquine as monotherapy or combined with azithromycin in COVID-19 treatment. Sci Rep 2020;10(1):1-18.

44. Gasperetti A, Biffi M, Duru F, et al. Arrhythmic safety of hydroxychloroquine in COVID-19 patients from different clinical settings. Europace 2020;22(12): 1855-63.

45. Mazzanti A, Briani M, Kukavica D, et al. Association of hydroxychloroquine with QTc interval in patients with COVID-19. Circulation 2020;142(5):513-5.

46. Thémans P, Belkhir L, Dauby N, et al. Population pharmacokinetics of hydroxychloroquine in COVID19 patients: implications for dose optimization. Eur J Drug Metab Pharmacokinet 2020;45(6):703-13.

47. Bernardini A, Ciconte G, Negro G, et al. Assessing QT interval in COVID-19 patients:safety of hydroxychloroquine-azithromycin combination regimen. Int J Cardiol 2021;324:242-8.

48. Chorin E, Wadhwani L, Magnani S, et al. QT interval prolongation and torsade de pointes in patients with COVID-19 treated with hydroxychloroquine/azithromycin. Heart Rhythm 2020;17(9):1425-33.

49. Cao B, Wang Y, Wen D, et al. A trial of lopinavirritonavir in adults hospitalized with severe Covid19. N Engl J Med 2020;382(19):1787-99.

50. Owa AB, Owa OT. Lopinavir/ritonavir use in Covid19 infection: is it completely non-beneficial? J Microbiol Immunol Infect 2020;53(5):674-5. 
51. Haghjoo M, Golipra R, Kheirkhah J, et al. Effect of COVID-19 medications on corrected QT interval and induction of torsade de pointes: results of a multicenter national survey. Int J Clin Pract 2021; 75(7):e14182.

52. Mohanty S, Di Biase L, Mohanty P, et al. Effect of periprocedural amiodarone on procedure outcome in patients with longstanding persistent atrial fibrillation undergoing extended pulmonary vein antrum isolation: results from a randomized study (SPECULATE). Heart Rhythm 2015;12(3):477-83.

53. Zhu S, Wang J, Wang Y, et al. QTc prolongation during antiviral therapy in two COVID-19 patients. J Clin Pharm Ther 2020;45(5):1190-3.

54. Gupta AK, Parker BM, Priyadarshi V, et al. Cardiac adverse events with remdesivir in COVID-19 infection. Cureus 2020. https://doi.org/10.7759/cureus. 11132.

55. Çap M, Bilge Ö, Ișık F, et al. The effect of favipiravir on QTc interval in patients hospitalized with coronavirus disease 2019. J Electrocardiol 2020;63:115-9.

56. Çelik HG, Keske Ș, Șener Ü, et al. Why we should be more careful using hydroxychloroquine in influenza season during COVID-19 pandemic? Int J Infect Dis 2021;102:389-91.

57. Nakamura Y, Sasaki R, Cao X, et al. Intravenous antiinfluenza drug oseltamivir will not induce torsade de pointes: evidences from proarrhythmia model and action-potential assay. J Pharmacol Sci 2016; 131(1):72-5.

58. Butler CC, Dorward J, Yu LM, et al. Azithromycin for community treatment of suspected COVID-19 in people at increased risk of an adverse clinical course in the UK (PRINCIPLE): a randomised, controlled, open-label, adaptive platform trial. Lancet 2021;397(10279):1063-74.

59. Lazzerini PE, Acampa M, Capecchi PL, et al. Antiarrhythmic potential of anticytokine therapy in rheumatoid arthritis: tocilizumab reduces corrected qt interval by controlling systemic inflammation. Arthritis Care Res 2015;67(3):332-9.

60. Panoulas VF, Toms TE, Douglas KMJ, et al. Prolonged QTC interval predicts all-cause mortality in patients with rheumatoid arthritis: an association driven by high inflammatory burden. Rheumatol (Oxford) 2014;53(1):131-7.

61. Stone JH, Frigault MJ, Serling-Boyd NJ, et al. Efficacy of tocilizumab in patients hospitalized with Covid-19. N Engl J Med 2020;383(24):2333-44.

62. Rosas IO, Bräu N, Waters M, et al. Tocilizumab in hospitalized patients with severe Covid-19 pneumonia. N Engl J Med 2021;384(16):1503-16.

63. Lazzerini PE, Laghi-Pasini F, Acampa M, et al. IL-6 (interleukin 6) blockade and heart rate corrected QT interval prolongation in COVID-19. Circ Arrhythm Electrophysiol 2020;13(9):e008791.

64. Pasin L, Cavalli G, Navalesi P, et al. Anakinra for patients with COVID-19: a meta-analysis of nonrandomized cohort studies. Eur J Intern Med 2021; 86:34-40.

65. Giudicessi JR, Noseworthy PA, Friedman PA, et al. Urgent guidance for navigating and circumventing the QTC-prolonging and torsadogenic potential of possible Pharmacotherapies for Coronavirus Disease 19 (COVID-19). Mayo Clin Proc 2020;95(6): 1213-21.

66. Drugs to be avoided by congenital long QT patients. Available at: www.crediblemeds.org. Accessed July 18, 2021. 